\title{
ARDUINO BASED NOVEL E-FARMING TECHNOLOGY USING WIRELESS SENSOR NETWORKS
}

\author{
T.C.Swetha Priya \\ Assistant Professor \\ Department of Information Technology \\ Stanley College of Engineering and Technology for \\ Women \\ Hyderabad, Telangana, India
}

\begin{abstract}
Mostly 70\% of Indian population depends on Agriculture and the revenue associated with their products. The demand for food crops and agriculture increases day by day as the world's population grow. So, there is a need to solve many problems associated with the agriculture due to which there is a reduction in the crop production. The productivity in the field of agriculture may reduce due to so many factors like changes in weather, environment, moisture, lack of awareness about latest technology. There comes the need for a Wireless Sensor Network (WSN) to monitor the problems related to the crop productivity and agriculture. Wireless Sensor Networks play a major role in the field of Agriculture. So, in the proposed system, a Wireless Sensor Network is used to monitor the changes in weather, environment, water supply to crops, moisture level in the fields and the rate at which pests damage the crop. In this system, different types of sensors, devices and components are used to capture the details about crop fields so as to take preventive actions before damage occurs. The gathered information from these different sensors is recorded and sent to the farmer's smart phone. Based on this the farmer will take appropriate action which helps him in taking appropriate actions and improving the crop productivity.
\end{abstract}

Keywords-Wireless Sensor Network, Sensors, Arduino, Moisture, Smart Phone, Humidity, Server

\section{INTRODUCTION}

The backbone of Indian income lies in Agriculture. But in recent times it is seen that the progress in the field of agriculture is getting reduced leading to less income to government. One of the reason is that in India, still farmers are following traditional farming which causes more effort and make farmers poor due to low productivity (Sreekantha et al. 2017), (Balaji et al. 2014). Many advancements have took place recently in terms of equipment and methods in the agriculture sector but due to the lack of education, awareness

\author{
Dr.A.Kanaka Durga \\ Professor, HOD \\ Department of Information Technology \\ Stanley College of Engineering and Technology for \\ Women \\ Hyderabad, Telangana, India
}

and proper knowledge to farmers they could not use the technology efficiently leading to non-profitable yields. A figure depicting the difference between Traditional Farming and E-Farming is shown in Figure.1.

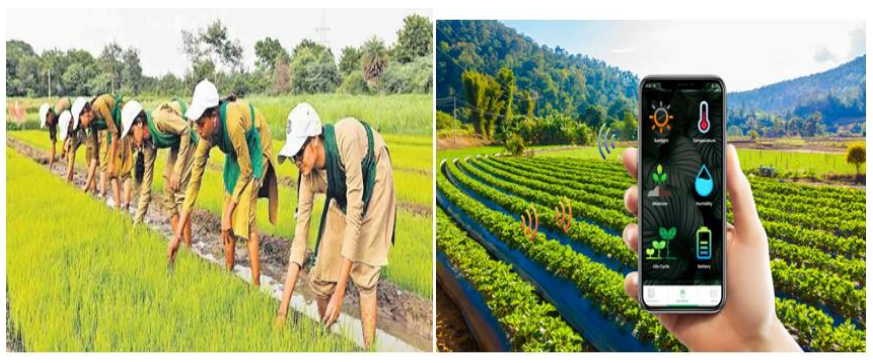

Fig 1. Traditional Farming Vs E-Farming

The main idea behind the proposed framework is by using the different types of sensors the different parameters or features like environment, moisture, humidity, pests, weather, water supply, crop rotation recommendation related information is captured. To capture this information, the Wireless Sensor Networks play a vital role.

\section{WIRELESS SENSOR NETWORKS}

A Wireless Sensor Network is a network consisting of a distributed set of Sensors operating autonomously monitoring the various conditions like weather, environment, temperature, moisture, etc. The applications of WSN have a wider range such as Smart home monitoring, Health Care monitoring, Military fields, Agriculture, Weather Forecasting, Temperature Sensing, Earthquake detection, Rainfall prediction, Fire detection etc.

A Wireless Sensor Network consist of a set of sensor nodes which gathers the information at a particular location and this information is disseminated to the main node or sink node. This sink node has complete information gathered from all the sensors about the location where this network is setup. This sink node is attached to a smart phone. Then through this 
sink node the collected reports will be sent to the smart phone. Based on these, the smart phone user will take appropriate action. Based on the action chosen by Smartphone user an appropriate function will be activated and is performed. Using WSN has an improvement over previous situations where everything has to be done manually by the farmers. The operation of a WSN is shown in Figure 2.

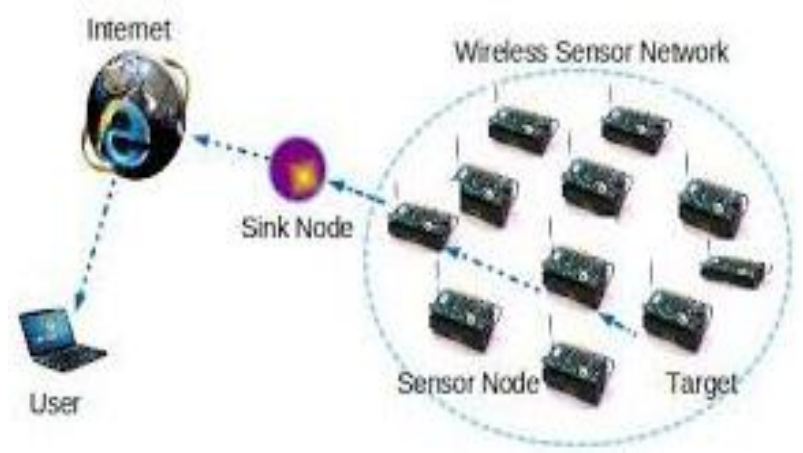

Fig 2 Operation of Wireless Sensor Network

\section{A. Architecture of a Wireless Sensor Network -}

A Wireless Sensor Network consists of three main components : Base Station, Wireless Sensors, and Wireless links. All the wireless Sensors are connected through wireless technology such as Zigbee, Wireless Ethernet, Wifi, etc., The WSN architecture is depicted in Figure 3.

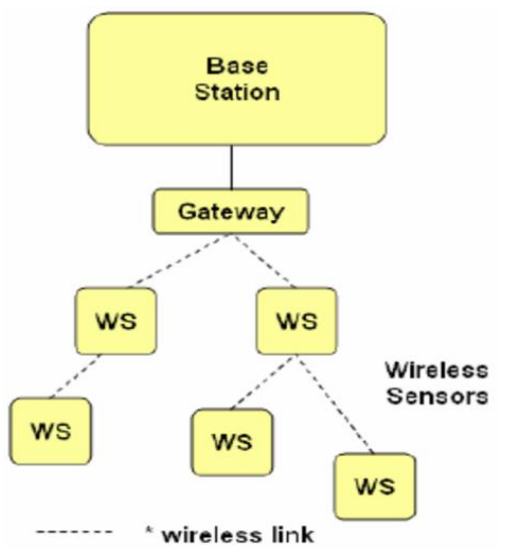

Fig 3 Architecture of WSN

A WSN can consist of any number of Wireless Sensors. The Wireless sensors are set up at a particular location. These Wireless Sensors gather the information and send data to Gateway which in turn sends information to Base Station.

\section{B. Sensors -}

A sensor is a specially designed component to detect the changes happening in the physical and environmental conditions such as weather, moisture, temperature, humidity, pressure, etc.,. The architecture of a Wireless Sensor is shown in Figure 4.

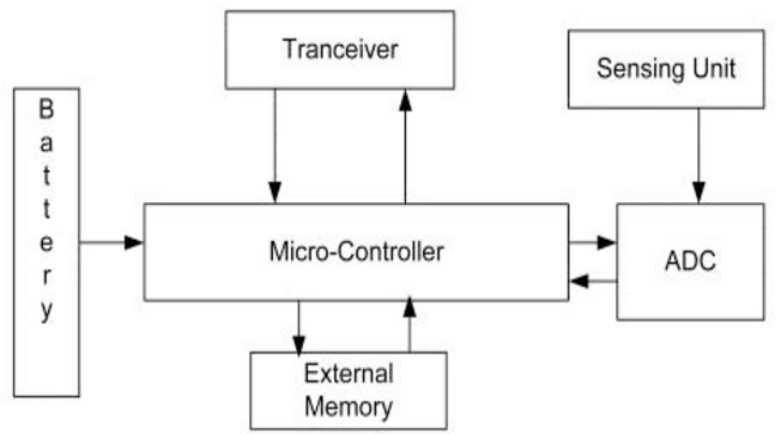

Fig 4 Architecture of Wireless Sensor

A sensor captures, organizes and manages the collected data about a particular location. There are different types of sensors used in this application.

\section{i. Optical sensor}

These sensors use light source to monitor the properties of soil such as moisture level, humidity level, water level, clay type etc. An Optical Sensor is depicted in Figure 5
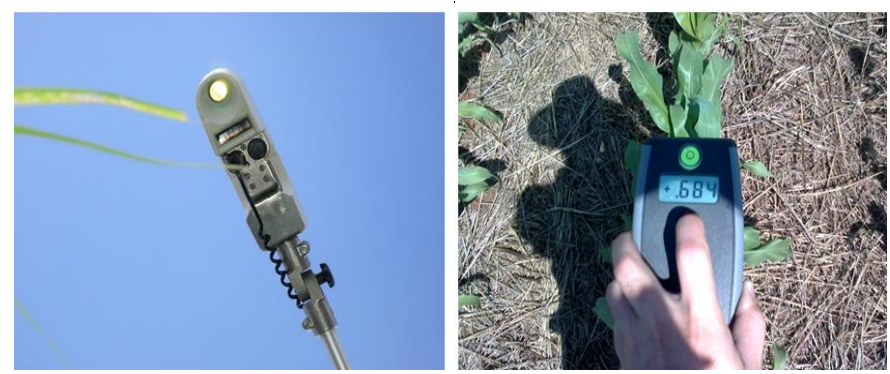

Fig 5 Optical Sensor

ii. Speed sensor

The Speed sensor used in this application is GPS Based sensor or a Radar technology based sensor to control the devices connected to other sensors. A Speed Sensor is depicted in Figure 6.

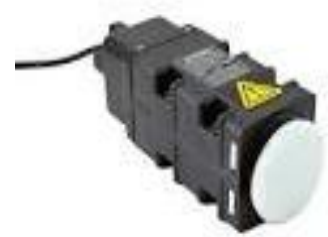

Fig 6 Speed Sensor

iii. Smoke detector

These type of detectors are used to detect the fire accidents occurring in the farm fields. This also helps in early detection and prevention of accidents. 


\section{International Journal of Engineering Applied Sciences and Technology, 2020 \\ Vol. 5, Issue 1, ISSN No. 2455-2143, Pages 417-422 \\ Published Online May 2020 in IJEAST (http://www.ijeast.com)}

\section{iv. Humistor}

This is a Humidity Sensor. It is used to compute the amount of water present in the air. This suggests the amount of water required for the crops. A Humistor is depicted in Figure 7.

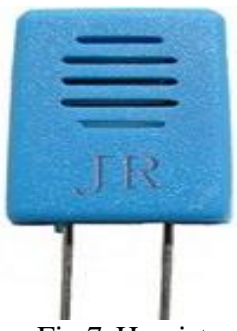

Fig 7 Humistor

\section{v. Rain sensor}

A rain sensor is a device which gets activated upon rainfall. It is mainly used to preserve the water that is wasted from rainfall. Upon detection of rainfall the regular motor water supply to the crops is shutdown and the rain water is used for irrigation. Another purpose of this sensor is in water Harvesting. A Rain Sensor is depicted in Figure 8.

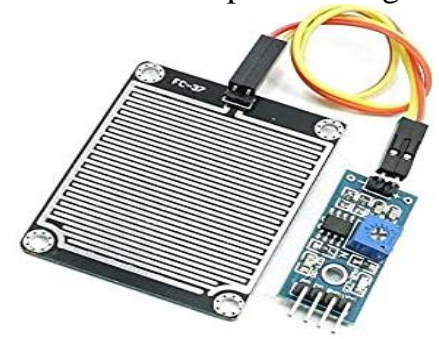

Fig 8 Rain sensor

\section{vi. Soil moisture sensor}

These sensors are used to determine the level of water content in the soil. This is helpful in watering the crop at appropriate levels. A Soil moisture Sensor is depicted in Figure 9.

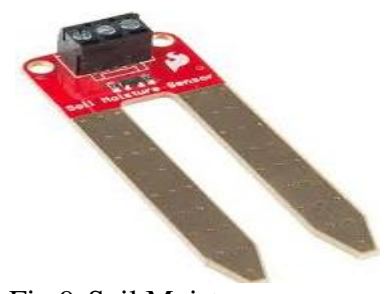

Fig 9 Soil Moisture sensor

\section{vii. LED as light sensor}

This sensor is used to show a light as an indication to the farmer about some inappropriate situations happening in the crop field.

\section{viii. Level sensor}

This sensor is used to analyze the amount of liquid or any other fluid like items present in the soil. For example in the agriculture fields, the level sensors may be used to take a decision about digging bore wells. A Level Sensor is depicted in Figure 10.
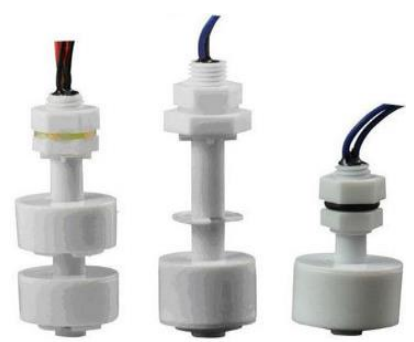

Fig 10 Level sensor

\section{ix. Touch Sensor}

This sensor is used to identify and record any physical touch to the crops. This is used to prevent the damage caused by insects, pests and any calamities caused by other sources by detecting the movement of a person or pest. This touch sensor has inbuilt mechanism of image processing to identify and record the different entity details for detecting the crop diseases and the pests on the fruits. The information is then sent to the farmers. A Touch Sensor is depicted in Figure 11.

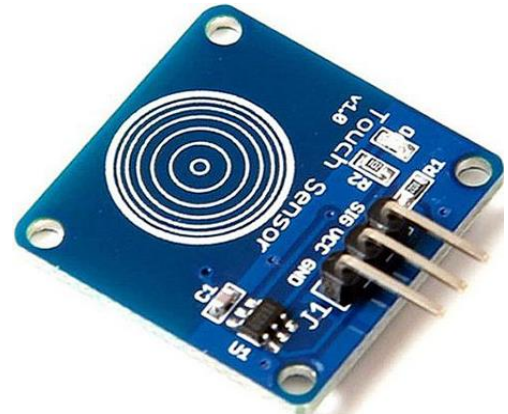

Fig 11 Touch sensor

\section{x. Acoustic sensor}

This type of sensor is a electronic device that is used to compute the level of sound. This sensor can be used in crop fields to record the sound levels of insects and any other type of insects spoiling the crops. Based on these sounds, an alert will be sent to phone about high or low level of pests and based on that appropriate pesticides are used to improve the productivity of fields.

\section{RELATED WORK}

Most of the existing works concentrate on the concept of smart farming. Mohamed Ra widean et al. (2014), J. Infantial Rubalal et al. (2017) concentrate on how the green 


\section{International Journal of Engineering Applied Sciences and Technology, 2020 \\ Vol. 5, Issue 1, ISSN No. 2455-2143, Pages 417-422 \\ Published Online May 2020 in IJEAST (http://www.ijeast.com)}

house gases affect agriculture. Their work concentrates on computing humidity and limiting the water supply and temperature changes based on moisture present in the soil. It solves the problem of green house effect by implementing intelligent green house management system in precision agriculture. But this can solve only some problems of agriculture. Awati J.S et al. (2012), J. Infantial Rubalal et al. (2017) concentrate on how the environment changes and global warming conditions affect agriculture. Their work concentrates on computing humidity and limiting the water supply and temperature changes based on moisture present in the soil. Ihsan Ali et al. (2018) proposed a decision support system that is used to identify the sites where there is deficiency in water and informs this to farmers by generating an alarm. They used the sensors for detecting and collecting soil moisture and environment data. But this concentrates on only some factors influencing the soil content. N. Sakthi priya et al. (2014), Jawahar Shree Ram et al. (2019) in their work aims in predicting the type of crop based on the calculated temperature, water-level, humidity, ph values of soil. They deployed different types of sensors which will gather information about the soil and applies different machine learning techniques to analyze the patterns in information and this is used to expect the future conditions and for crop recommendation. But none of these works have taken into account the complete problems or parameters of the soil that may affect the productivity of the crop leading to reduction in the profits to the farmers making them poor.

\section{PROPOSED WORK}

The proposed system implements agriculture using the latest technologies which automates most of the work done by farmer manually earlier. Previously, the farmers used traditional methods in combination with some sensors only which could be able to detect only some features of soil. Now, in the proposed work by deploying the different kind of sensors such as Light sensor, Level Sensor, Humistor, Soil Moisture Sensor, Acoustic Sensor, Touch Sensor, Rain Sensor, Smoke Sensor and Speed Sensor all the parameters related to the crop soil are recorded. All the sensors are connected through Wireless medium and they form a Wireless Sensor Network. The details are recorded by all the sensors and is captured by the Base Station and the information is forwarded to the Farmer's Smartphone. The flowchart for the working model is depicted as shown in Figure 12.

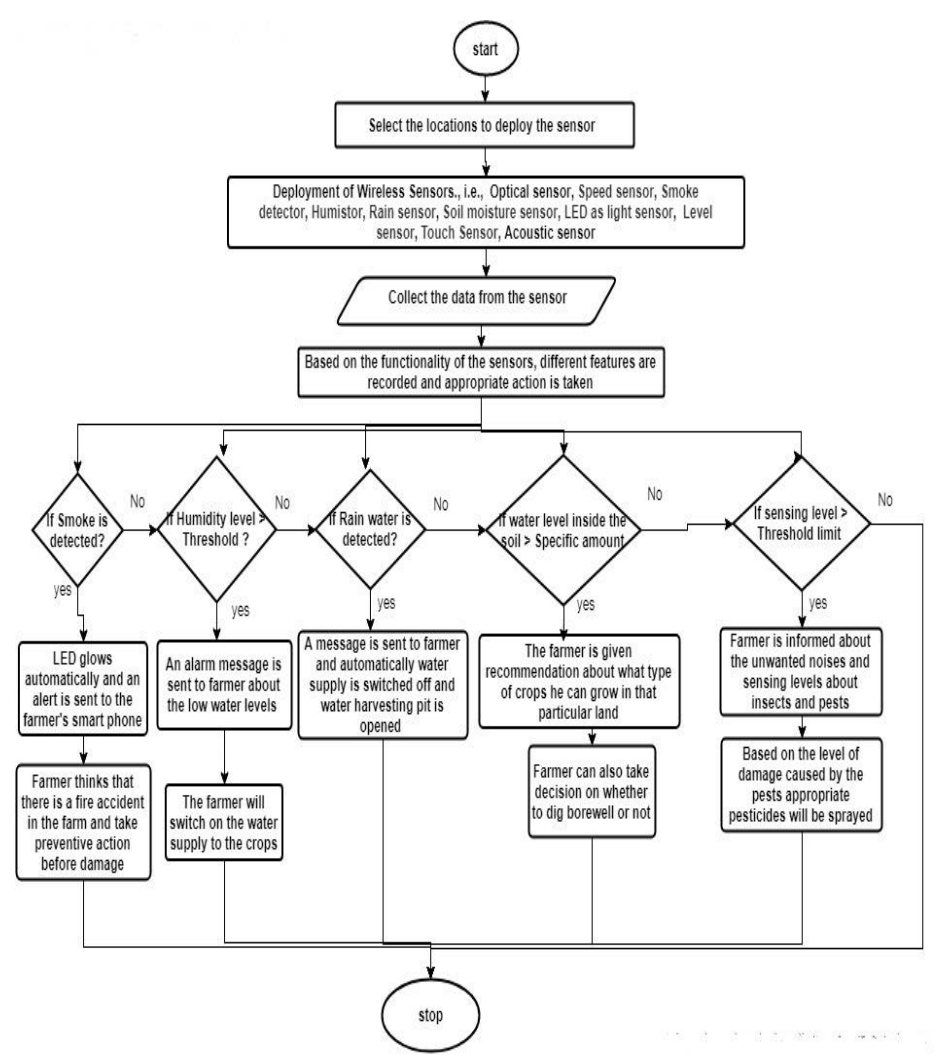

Fig 12 Flow Chart for the working model

\section{IMPLEMENTATION}

The proposed work employs an Arduino Uno R3 board which is a microcontroller board that is based on ATmega328 consisting of 20 input/output pins, a power port, reset button, ground, a USB controller, crystal oscillator, USB interface chip, Transceiver LED, Receiver LED, Analog input pins and ports to connect other pins.

The proposed system connects Arduino Uno R3 to the power supply, Rectifier, a Regulator to regulate the power supply to the Arduino board. Now one port of the the Acoustic Sensor, Temperature sensor, Touch sensor, Rain sensor, Soil moisture sensor, Level sensor, Light Sensor and Smoke detector are connected to the different pins of the Arduino board and the other port is shorted to ground pin. All these sensors gather the respective information for which they have been built. All these sensors are connected through Wifi module. This data captured by sensors is recorded and is stored in the Wifi module and data is sent to the Base Station (Website). The same data is sent to the farmer's smart phone through GSM module which is connected to the Arduino Uno R3 board. Figure 13 depicts how the proposed system works. 


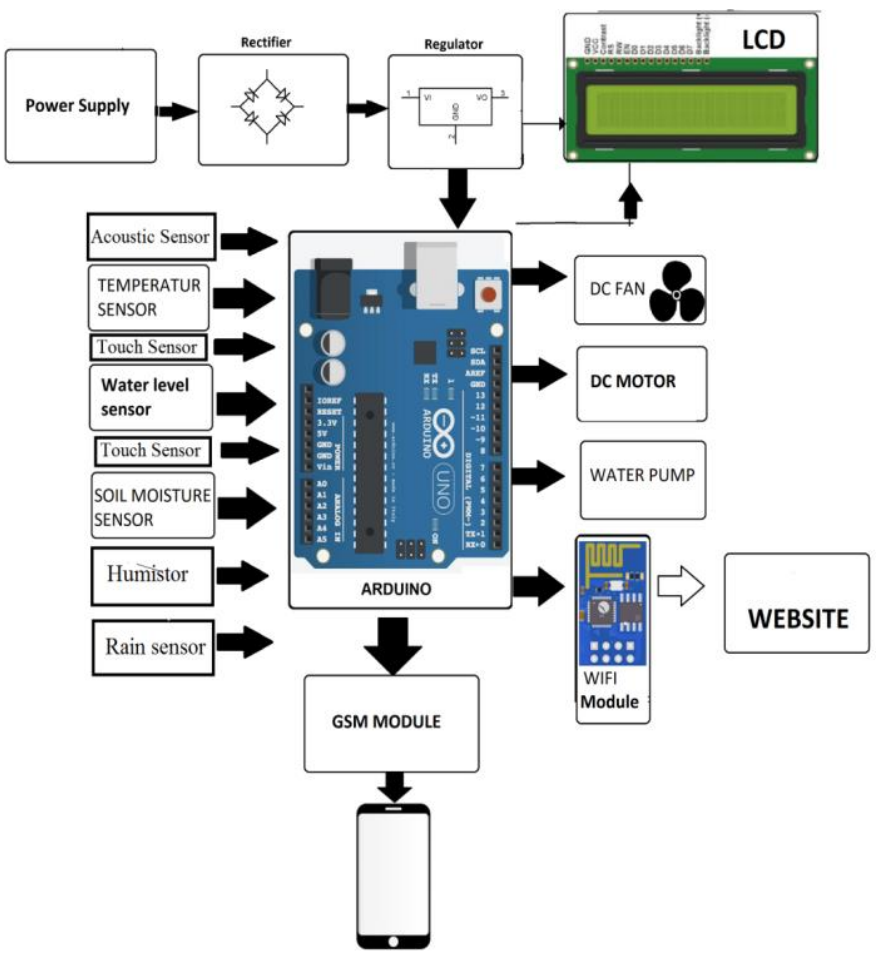

Fig 13 Implementation of the proposed system using Arduino Uno R3

Thus, the farmer will get the details about the various parameters about the soil by deploying these many sensors and he can take appropriate actions. The Humistor, Level Sensor and soil moisture sensor is used to detect the humidity and water levels in the soil which will be helpful to the farmer to know whether the fields are dry or wet. If the crop is dry means, low water levels are detected then alert is sent to farmer regarding this and then he switches the water supply. If the field is wet, then the regular motor water supply is stopped.

The Rain sensor gets activated when it detects the significant levels of rainfall and a message alert is sent to the farmer's mobile phone. Then the farmer will stop the motor water supply and rain water is allowed to water the crop. If there is sufficient rain water to the crop, then the extra rain water will be saved in the harvesting pit.

The Smoke sensor activates when a significant amount of smoke is detected due to fire accident or any other natural disaster in the location where the sensor is setup. Immediately a message is sent to the farmer regarding the situation and farmer will initiate an immediate action to prevent the consequences of the incident. Previously, the farmer notices the odd situations only after half of the damage has happened.

The acoustic sensor is used in the fields to sense the sound levels in the crop fields. The sound levels may include the sounds made by insects, pests or any other kinds of creatures causing damage to the crops. Then the level of sound intensity is recorded in the LCD. Then the sound level is compared to the threshold value that is already set. If it is more than threshold value then an alert is sent to farmer. Then the farmer will switch on the pesticide sprinkler to the crops.

All these sensors will report some or the other information on the Liquid Crystal Display (LCD) board connected to the Arduino board. Based on the computed parameters like moisture, humidity and water levels in the soil, the farmer will also get the crop recommendations i.e., which crop is suitable for the soil.

\section{CONCLUSION AND FUTURE SCOPE}

This paper proposes a novel E-Farming technology by deploying multiple sensors over the multiple locations of crop fields which will monitor the different parameters of soil and informs the farmers about the abnormal activities in the field. Also the proposed work focuses on giving recommendations on the smart phone to the farmer about what type of crops can be suitable for that place to grow by analyzing and taking into consideration all aspects that are collected from multiple sensors. Thus, the proposed work can enhance the crop productivity to some extent.

As this proposed scheme uses multiple sensors, the data that gets captured also increases over time. In future, this idea can be extended by implementing a cloud instead of storing the gathered data on a Website/Server.

\section{REFERENCES}

[1] Mohamed Ra widean, Mohd Kassim, Ibrahim Mat, (2014), "Wireless Sensor Network in Precision Agriculture Application", Ministry of Science, Technology and Innovation Kuala Lumpur, IEEE,. https://doi.org/10.1109/CITS.2014.6878963

[2] Awati J.S., Patil V.S. And Awati S.B., (2012) "Application Of Wireless Sensor Networks For Agriculture Parameters", International Journal Of Agriculture Sciences. Volume 4, Issue 3, 2012, pp-213215.

[3] D.K. Sreekantha, Kavya.A.M", (2017), "Agricultural Crop Monitoring using IOT- A Study", Department of Computer International Journal of Engineering Science and Computing, 11th International Conference on Intelligent Systems and Control (ISCO), https://doi.org/10.1109/ISCO.2017.7855968

[4] J. Infantial Rubala1, D. Anitha, (2017), "Agriculture Field Monitoring using Wireless Sensor Networks to Improving Crop Production", IJESC, pp-5216-5221

[5] Ihsan Ali, Muhammad Imran, Muhammad Za-karya, Rahmin Khan, (2018), “Technology-Assisted Decision Support System for Efficient Water Utilization: A RealTime Test bed for Irrigation Using Wireless Sensor Networks," IEEE Access, vol. 6, no. 6, pp. 2342-2350,

[6] Jawahar Shree Ram R, Keerthi K, Ritesh A, Amirtha Sughi D, , (2019), " A Novel Approach To Smart Farming", International Research Journal of Engineering 
and Technology (IRJET) e-ISSN: 2395-0056, Volume: 06 Issue: 03, pp-3232-3238.

[7] B. Balaji Bhanu, K. Raghav Rao, J. V. N. Ramesh, Mohammed Ali Hussain, (2014), "Agriculture Field Monitoring and Analysis using Wireless Sensor Networks for improving Crop Production", IEEE, https://doi.org/10.1109/WOCN.2014.6923043.

[8] G. Nikesh, R.S. Kawitkar, (2016), "Smart Agriculture Using IoT and WSN Based Modern Technologies". International Journal of Innovative Research in Computer and Communication Engineering, 4(6), pp. 12070-12076,

[9] K. Shinghal and S. Neelam. (2017), "Wireless Sensor Networks in Agriculture: For Potato Farming", SSRN, pp. 3955-3963.

[10] Arvind.G, Athira.V.G, Haripriya.H ,Akshaya Rani. R, Aravind.S, (2017) , "Automated irrigation with advanced seed germination and pest control", IEEE International Conference on Technological Innovations in ICT For Agriculture and Rural Development, https://doi.org/10.1109/TIAR.2017.8273687

[11] Divya J, Divya M, Janani V, (2017), "IoT based Smarts Soil Monitoring Systems for Agricultural Production", IEEE Internationals Conference on Technological Innovations in ICT for agriculture and Rural Development,https://doi.org/10.1109/TIAR.2017.827371 7

[12] G.Yanxia, Wu Baozhong Ren Zhenhui, (2018), "Research of Precision Farming Expert System Based on GIS", Notulae Scientia Biologicae, Vol 10, https://doi.org/10.1109/ICEMI.2007.4350815

[13] Preetha Rajan, Radha krishnan. B, Dr. L. Padma Suresh, (2016), "Detection And Classification Of Pests From Crop Images Using Support Vector Machine", International Conference on Emerging Technological Trends, https://doi.org/10.1109/ICETT.2016.7873750

[14] N. Sakthi priya, (2014), "An Effective Method for Crop Monitoring Using Wireless Sensor Network", MiddleEast Journal of Scientific Research, IDOSI Publications, https://dx.doi.org/10.5829/idosi.mejsr.2014.20.09.114152 